\title{
A Study of Food Consumption Patterns in Patients with Gastric Cancer in Mazandaran
}

\author{
Mahmoud Hajiahmadi ${ }^{1}$, Javad Shokri-Shirvani² ${ }^{2}$ Dariush Moslemi ${ }^{3}$, Soleiman Hasanzadeh ${ }^{4}$, \\ Parvin Sajadi Kaboodi ${ }^{4}$ \& Soheil Ebrahimpour ${ }^{5}$ \\ ${ }^{1}$ Department of Statistic and Epidmiology, School of Medicine, Babol University of Medical Sciences, Babol, I.R \\ Iran \\ ${ }^{2}$ Department of Internal Medicine, School of Medicine, Babol University of Medical Sciences, Babol, I.R Iran \\ ${ }^{3}$ Radiological Technology Department, Faculty of Paramedical Sciences, Babol University of Medical Sciences, \\ Babol, I.R. Iran \\ ${ }^{4}$ Department of Social Medicine, School of Medicine, Babol University of Medical Sciences, Babol, IR. Iran \\ ${ }^{5}$ Infectious Diseases and Tropical Medicine Research Center, Health Research Institute, Babol University of \\ Medical Sciences, Babol, I.R. Iran \\ Correspondence: Parvin Sajadi Kaboodi, Department of Social Medicine, School of Medicine, Babol University \\ of Medical Sciences, Babol, IR. Iran. Tel: 98-911-114-8704. Email: psajadi@yahoo.com
}

Received: June 3, 2017

doi:10.5539/jmbr.v7n1p106
Accepted: June 20, 2017

Online Published: July 8, 2017

URL: https://doi.org/10.5539/jmbr.v7n1p106

\begin{abstract}
Gastric cancer is one of the most common types of cancer. There are geographical and racial differences in the prevalence of gastric cancer in different societies. The present study aims to investigate the food consumption patterns in patients with gastric cancer in Mazandaran. This case-control study was conducted among 100 patients with gastric cancer and 200 healthy controls. Two questionnaires including demographic information, and food frequency were completed by all participants. The mean frequency of consuming raw onions, fried onions, cucumbers and salted vegetables, red meat (beef and lamb), eggs, burgers, pizza, soy, pasteurized milk, yogurt, ice cream, liquid oil, cream, tea, pumpkin and sunflower seeds, chocolate and dates in the case group was more than control group. Findings of the current research showed that some foods such asvegetables, fish, rice and dairy are extensively found in the dietary patterns in northern of Iran.These are considered as preventive factorsin the incidence of gastric cancer.
\end{abstract}

Keywords: Gastric cancer, dietary habits, nutrition, food frequency questionnaire, anthropometry questionnaire

\section{Introduction}

Gastric cancer is one of the most common types of cancer in Iran and in the world. The prevalence of gastric cancer is varied in different geographical areas. The risk of gastric cancer is higher in lower socio-economic classes. So, high-incidence regions for gastric adenocarcinoma contain Eastern Europe, East Asia and South America. Low incidence rates are found in North Africa and America(Crew \& Neugut, 2006).In Iran, gastric cancer are usual fatal carcinoma and their incidence rates are upper than the world's average. For example, Ardabil Province located in cancers inthis country with the age standard incidence ratesof within 20 and 50 for females and males, respectively (Malekzadeh, 2013).Moreover, the northern areas are high risk regions for gastric cancer, there are different intermediate risk populations (Malekzadeh, Derakhshan\& Malekzadeh,2009).in other geographical areas Pathologically speaking, $85 \%$ of gastric cancers are adenocarcinomas and 15 percent of them are lymphoma and leiomyosarcoma(Mager, 2006; Thun, DeLancey, Center, Jemal, \& Ward, 2010). The global prevalence of gastric cancer has decreased quickly in recent decades. However, the causes of this reduction are not clear yet. On the other hand, the reduction ratio was not the same in different regions. The histological pattern of gastric cancer has also changed from intestinal type to diffuse type (Hu et al., 2012).Currently, gastric cancer screening is very difficult and costly. Therefore, primary prevention strategies are preferred over therapeutic interventions to control this disease (Park, von Karsa, \& Herrero, 2014). The efficiency of primary prevention strategies depends on our knowledge regarding the associated risk factors. Some risk factors for gastric cancer include helicobacter pylori, blood type A, chronic gastritis, smoking cigarettes, use of alcoholic drinks, occupational exposures, environmental 
exposures, use of meat including bacon and fermented meat, smoked and fermented foods, common smoked foods and meat products(Derakhshan, 2013; Edgren et al., 2010; Zali, Rezaei-Tavirani, \& Azodi, 2011). Dietary habits are discussed regarding region. High nitrate concentrations in dried, smoked or salted food increase the chance of cancer (Jakszyn\& González, 2006). Nitrates transform into carcinogenic nitrates by bacteria (Tiso\& Schechter, 2015). These bacteria enter the patient's body through consumption of decaying foods. Helicobacter pylori can also play a role in this process by creating chronic gastritis and eliminating acidity (Kusters, van Vliet, \& Kuipers, 2006). In spite, a clear negative correlation between cancers particularly, gastric cancer and eating fruits and vegetables, garlic and drinking tea has been reported (FALLAH \& EBRAHIMPOUR, 2015; González et al., 2006; Hou, Amarnani, Chong, \& Bishayee, 2013).

However, exposure to these risk factors depends on time, place and the community's social characteristics. Therefore, considering the high prevalence of gastric cancer in Iran particularly the Northern provinces, the present study was conducted to determine the risk factors of gastric cancer such as dietary habits and their relationship with this type of cancer in Mazandaran.

\section{Materials and Methods}

This case-control study was conducted among 100 patients with gastric cancer hospitalized in educational hospitals (Babol University of Medical Sciences, Babol, Iran) whose disease was confirmed by a specialist, as case group as well as 200 healthy people as the control group. The primary gastric cancer was diagnosed by reviewing medical records with tissue samples confirmed by a pathologist as adenocarcinoma. Then, two standard questionnaires were completed including: demographic information questionnaire (such as age, gender, economic status, occupation, etc.), and food frequency questionnaire within one month. Two questionnaires were completed by interviewers.

\subsection{Statistical Analysis of Data}

The data were collected and codified. After recording the data in the designed tables, they were statistically analyzed by SPSS ver. 16 . The collected data were illustrated using frequency tables and related charts. The data were analyzed using statistical tests including $\mathrm{Chi}$ - square and T-test.

\section{Results}

Of the 300 studied people, 150 people (50\%) lived in the western region of the province, 48 people (16\%) lived in the eastern region of the province, 98 people (32.7\%) lived in the center of the province and the rest lived outside the province. The difference between the two groups in term of residence was not significant ( $>0.05)$. The mean duration of residence in the area was $28.54 \pm 13.34$ years for case group and $36.03 \pm 17.31$ years for control group $(\mathrm{p}=0.001)$. Overall, 136 people $(45.3 \%)$ were female while 164 people $(54.7 \%)$ were male. There was a significant difference between the case and control groups regarding gender $(\mathrm{p}=0.000)$. Regarding education, 85 people $(28.3 \%)$ were illiterate, 56 people $(18.7 \%)$ had primary education, 51 people $(17 \%)$ had secondary education and 108 people $(36 \%)$ had high school degree or higher. There was a significant difference between the case and the control groups regardingthe level of education $(\mathrm{p}=0.001)$. Among the studied people, 4 people $(1.3 \%)$ were unemployed, 84 people $(28 \%)$ were employees, 43 people $(14.3 \%)$ were workers, 110 people $(36.7 \%)$ were housewives, 38 people $(12.7 \%)$ were self-employed and 21 people $(7 \%)$ had other occupations. The difference between the two groups was statistically significant $(\mathrm{p}=0.004)$. Of these people, 24 people $(8 \%)$ were single and 276 people $(92 \%)$ were married; the difference between the two groups was significant $(\mathrm{p}=0.002)$. In terms of economic status, 11 people (3.7\%) had high economic status, 231 people $(77 \%)$ had average economic status and 58 people (19.3\%) had low economic status. There was no significant difference between the two groups in term of economic status ( $\mathrm{p}=0.582$ ) (Table 1). The mean frequency of food consumption in the two groups of case and control was compared in Table 2.This table showed that, high frequency of food consumption in case group were tea(70.98 \pm 3.05$)$, salt ( $63.16 \pm 2.77)$, bread ( 54.181 .34$)$ and in control tea $(83.21 \pm 2.88)$, bread $(57.72 \pm 1.6)$, salt $(44 / 2 \pm 97 / 62)$ and fried onion $(18.73 \pm 1.14)$. 
Table 1. Demographic characteristics of patients under study

\begin{tabular}{|c|c|c|c|c|}
\hline & Demographic characteristics & $\begin{array}{l}\text { Case } \\
\mathrm{N}(\%) \\
\end{array}$ & $\begin{array}{r}\text { Control } \\
\mathrm{N}(\%) \\
\end{array}$ & P- value \\
\hline \multirow[t]{2}{*}{ Gender } & male & $38(38)$ & $126(63)$ & $\mathbf{S}$ \\
\hline & female & $62(62)$ & $74(37)$ & \\
\hline \multirow[t]{5}{*}{ Education level } & illiterate & $9(9)$ & $76(38)$ & $\mathbf{S}$ \\
\hline & Primary school & $11(11)$ & $45(22 / 5)$ & \\
\hline & Secondary school & $23(23)$ & $28(14)$ & \\
\hline & High school and higher & $57(57)$ & $51(25 / 5)$ & \\
\hline & unemployed & $2(2)$ & $2(1)$ & \\
\hline \multirow[t]{5}{*}{ Occupation } & employee & $35(35)$ & $49(24 / 5)$ & $\mathbf{S}$ \\
\hline & worker & $5(5)$ & $38(19)$ & \\
\hline & housewife & $43(43)$ & $67(33 / 5)$ & \\
\hline & Self-employed & $12(12)$ & $26(13)$ & \\
\hline & other & $3(3)$ & $18(9)$ & \\
\hline \multirow[t]{2}{*}{ Marital status } & single & $15(15)$ & $9(4 / 5)$ & $\mathbf{S}$ \\
\hline & married & $85(85)$ & $191(95 / 5)$ & \\
\hline \multirow[t]{3}{*}{ Economic status } & high & $4(4)$ & $7(3 / 5)$ & NS \\
\hline & average & $80(80)$ & $151(75 / 5)$ & \\
\hline & low & $16(16)$ & $42(21)$ & \\
\hline \multirow[t]{3}{*}{ Place of residence } & west & $34(34)$ & $116(58)$ & NS \\
\hline & east & $11(11)$ & $37(18 / 5)$ & \\
\hline & center & $55(55)$ & $47(23 / 5)$ & \\
\hline
\end{tabular}

Table 2. Comparingthe mean monthly food consumption in the studied people

\begin{tabular}{|c|c|c|c|c|}
\hline $\begin{array}{l}\text { Group } \\
\text { Food }\end{array}$ & $\begin{array}{c}\text { Case } \\
(n=100)\end{array}$ & $\begin{array}{l}\text { Control } \\
(\mathrm{n}=\mathbf{2 0 0})\end{array}$ & $\begin{array}{c}\text { Total } \\
(\mathrm{n}=\mathbf{3 0 0})\end{array}$ & P-value \\
\hline Raw garlic & $3 / 45 \pm 0 / 60$ & $3 / 87 \pm 0 / 50$ & $3 / 74 \pm 0 / 39$ & $0 / 452$ \\
\hline Fried Garlic & $2 / 56 \pm 0 / 42$ & $2 / 81 \pm 0 / 29$ & $2 / 73 \pm 0 / 24$ & $0 / 053$ \\
\hline Raw onion & $15 / 60 \pm 1 / 73$ & $12 / 72 \pm 1 / 16$ & $13 / 68 \pm 0 / 97$ & $0 / 040$ \\
\hline fried onion & $32 / 55 \pm 2 / 54$ & $18 / 73 \pm 1 / 14$ & $23 / 34 \pm 1 / 19$ & 0/001 \\
\hline $\begin{array}{l}\text { Pickled cucumbers } \\
\text { and vegetable }\end{array}$ & $6 / 21 \pm 0 / 94$ & $2 / 95 \pm 0 / 47$ & $4 / 03 \pm 0 / 45$ & 0/001 \\
\hline Smoked foods & $0 / 42 \pm 0 / 14$ & $0 / 39 \pm 0 / 09$ & $0 / 40 \pm 0 / 08$ & $0 / 595$ \\
\hline Fermented pickles & $5 / 88 \pm 0 / 96$ & $8 / 67 \pm 0 / 92$ & $7 / 75 \pm 0 / 69$ & $0 / 112$ \\
\hline Canned foods & $1 / 07 \pm 0 / 18$ & $1 / 03 \pm 0 / 22$ & $1 / 04 \pm 0 / 16$ & $0 / 940$ \\
\hline Beef & $7 / 41 \pm 0 / 72$ & $5 / 83 \pm 0 / 87$ & $6 / 36 \pm 0 / 63$ & 0/001 \\
\hline Lamb meat & $5 / 96 \pm 0 / 74$ & $8 / 74 \pm 0 / 83$ & $7 / 81 \pm 0 / 61$ & 0/001 \\
\hline Chicken & $13 / 05 \pm 1 / 86$ & $14 / 16 \pm 1 / 85$ & $13 / 94 \pm 1 / 27$ & $0 / 128$ \\
\hline Fish & $5 / 38 \pm 0 / 67$ & $4 / 55 \pm 0 / 41$ & $4 / 83 \pm 0 / 35$ & 0/207 \\
\hline Tuna & $0 / 99 \pm 0 / 17$ & $1 / 11 \pm 0 / 18$ & $1 / 06 \pm 0 / 14$ & $0 / 759$ \\
\hline Purtenance & $1 / 90 \pm 0 / 24$ & $2 / 51 \pm 0 / 61$ & $2 / 30 \pm 0 / 41$ & $0 / 650$ \\
\hline egg & $14 / 87 \pm 1 / 38$ & $10 / 86 \pm 0 / 91$ & $12 / 20 \pm 0 / 77$ & 0/001 \\
\hline Sausages & $1 / 39 \pm 0 / 35$ & $0 / 85 \pm 0 / 12$ & $0 / 03 \pm 0 / 14$ & $\mathbf{0} / \mathbf{1 3 7}$ \\
\hline Hamburger & $1 / 02 \pm 0 / 18$ & $0 / 60 \pm 0 / 11$ & $0 / 74 \pm 0 / 09$ & 0/004 \\
\hline Pizza & $0 / 58 \pm 0 / 15$ & $0 / 05 \pm 0 / 01$ & $0 / 23 \pm 0 / 05$ & 0/001 \\
\hline Bread & $54 / 18 \pm 1 / 34$ & $57 / 72 \pm 1 / 60$ & $56 / 54 \pm 1 / 16$ & $0 / 346$ \\
\hline Rice & $34 / 28 \pm 1 / 15$ & $37 / 04 \pm 1 / 49$ & $36 / 12 \pm 1 / 07$ & $0 / 354$ \\
\hline beans & $8 / 84 \pm 0 / 84$ & $8 / 86 \pm 0 / 56$ & $8 / 85 \pm 0 / 46$ & 0/771 \\
\hline Soy & $4 / 13 \pm 0 / 70$ & $2 / 52 \pm 0 / 22$ & $3 / 06 \pm 0 / 28$ & 0/008 \\
\hline Local milk & $8 / 81 \pm 1 / 21$ & $11 / 08 \pm 0 / 90$ & $10 / 32 \pm 0 / 72$ & $0 / 067$ \\
\hline Pasteurized milk & $11 / 90 \pm 1 / 47$ & $6 / 14 \pm 1 / 27$ & $8 / 06 \pm 0 / 99$ & 0/001 \\
\hline Regular yogurt & $27 / 28 \pm 1 / 38$ & $25 / 77 \pm 1 / 44$ & $26 / 28 \pm 1 / 06$ & 0/119 \\
\hline Strained yogurt & $3 / 59 \pm 0 / 65$ & $3 / 31 \pm 0 / 41$ & $3 / 40 \pm 0 / 35$ & $0 / 865$ \\
\hline Dough (water and yogurt) & $16 / 10 \pm 1 / 81$ & $8 / 49 \pm 0 / 21$ & $11 / 03 \pm 0 / 20$ & 0/006 \\
\hline
\end{tabular}




\begin{tabular}{lcccc} 
Ice cream & $6 / 97 \pm 1 / 02$ & $3 / 02 \pm 0 / 51$ & $4 / 34 \pm 0 / 49$ & $\mathbf{0 / 0 0 1}$ \\
Cheese & $21 / 68 \pm 2 / 48$ & $13 / 09 \pm 1 / 26$ & $15 / 95 \pm 1 / 20$ & $\mathbf{0 / 0 0 1}$ \\
Curd & $1 / 12 \pm 0 / 11$ & $1 / 22 \pm 0 / 10$ & $1 / 19 \pm 0 / 08$ & $\mathbf{0} / 749$ \\
Solid oils & $14 / 62 \pm 2 / 01$ & $36 / 25 \pm 2 / 43$ & $29 / 04 \pm 1 / 84$ & $\mathbf{0 / 0 0 1}$ \\
Liquid oil & $32 / 32 \pm 2 / 25$ & $13 / 58 \pm 1 / 36$ & $19 / 83 \pm 1 / 28$ & $\mathbf{0 / 0 0 1}$ \\
Butter & $7 / 74 \pm 0 / 99$ & $8 / 75 \pm 0 / 77$ & $8 / 42 \pm 0 / 61$ & $\mathbf{0 / 1 6 3}$ \\
Cream (Fatty surface of milk) & $2 / 56 \pm 0 / 57$ & $4 / 49 \pm 0 / 59$ & $3 / 85 \pm 0 / 44$ & $\mathbf{0 / 0 0 2}$ \\
Cream & $2 / 79 \pm 0 / 68$ & $2 / 18 \pm 0 / 31$ & $2 / 38 \pm 0 / 30$ & $\mathbf{0 / 5 4 1}$ \\
Beverage & $5 / 25 \pm 1 / 07$ & $4 / 10 \pm 0 / 58$ & $4 / 48 \pm 0 / 52$ & $\mathbf{0 / 4 3 6}$ \\
Tea & $70 / 98 \pm 3 / 05$ & $83 / 21 \pm 2 / 88$ & $79 / 14 \pm 2 / 19$ & $\mathbf{0 / 0 0 3}$ \\
Nuts & $3 / 17 \pm 0 / 68$ & $1 / 99 \pm 0 / 34$ & $2 / 39 \pm 0 / 32$ & $\mathbf{0 / 0 2 1}$ \\
sunflower and pumpkin seeds & $4 / 27 \pm 1 / 08$ & $1 / 64 \pm 0 / 22$ & $2 / 51 \pm 0 / 39$ & $\mathbf{0 / 0 0 1}$ \\
Pistachios & $3 / 91 \pm 0 / 62$ & $3 / 36 \pm 0 / 35$ & $3 / 54 \pm 0 / 31$ & $\mathbf{0 / 8 5 6}$ \\
Raw vegetables & $16 / 44 \pm 2 / 44$ & $14 / 29 \pm 0 / 90$ & $15 / 01 \pm 1 / 01$ & $\mathbf{0 / 8 1 7}$ \\
Cooked vegetables & $7 / 87 \pm 1 / 65$ & $8 / 27 \pm 1 / 64$ & $8 / 14 \pm 1 / 48$ & $\mathbf{0 / 8 2 0}$ \\
Fruit & $39 / 32 \pm 3 / 50$ & $34 / 98 \pm 1 / 63$ & $36 / 42 \pm 1 / 59$ & $\mathbf{0 / 7 1 4}$ \\
Citrus & $23 / 40 \pm 1 / 83$ & $20 / 87 \pm 1 / 63$ & $21 / 71 \pm 1 / 24$ & $\mathbf{0 / 1 2 6}$ \\
Sugar & $11 / 69 \pm 1 / 40$ & $11 / 36 \pm 1 / 27$ & $11 / 47 \pm 0 / 96$ & $\mathbf{0 / 1 3 9}$ \\
Honey & $6 / 71 \pm 0 / 96$ & $6 / 15 \pm 0 / 55$ & $6 / 33 \pm 0 / 48$ & $\mathbf{0 / 9 4 0}$ \\
Pastry & $4 / 07 \pm 0 / 58$ & $4 / 03 \pm 0 / 46$ & $4 / 04 \pm 0 / 36$ & $\mathbf{0 / 8 6 8}$ \\
Jam & $6 / 96 \pm 0 / 98$ & $6 / 51 \pm 0 / 76$ & $6 / 66 \pm 0 / 60$ & $\mathbf{0 / 3 0 5}$ \\
Chocolate & $5 / 11 \pm 0 / 83$ & $3 / 57 \pm 0 / 58$ & $4 / 08 \pm 0 / 48$ & $\mathbf{0 / 0 0 1}$ \\
Raisins & $3 / 96 \pm 0 / 84$ & $6 / 62 \pm 1 / 16$ & $5 / 74 \pm 0 / 82$ & $\mathbf{0 / 8 0 3}$ \\
Berry & $2 / 58 \pm 0 / 91$ & $2 / 74 \pm 0 / 65$ & $2 / 69 \pm 0 / 53$ & $\mathbf{0 / 2 6 4}$ \\
Date & $13 / 58 \pm 1 / 95$ & $5 / 39 \pm 0 / 79$ & $8 / 12 \pm 0 / 86$ & $\mathbf{0 / 0 0 1}$ \\
Tomato paste & $28 / 03 \pm 1 / 75$ & $27 / 02 \pm 1 / 46$ & $27 / 36 \pm 1 / 13$ & $\mathbf{0} / \mathbf{4 7 4}$ \\
Salt & $63 / 16 \pm 2 / 77$ & $62 / 97 \pm 2 / 44$ & $63 / 03 \pm 1 / 87$ & $\mathbf{0 / 5 4 6}$ \\
Cereals & $34 / 66 \pm 3 / 93$ & $33 / 91 \pm 3 / 48$ & $34 / 16 \pm 2 / 66$ & $\mathbf{0 / 5 8 3}$ \\
\hline & & & &
\end{tabular}

\section{Discussion}

In current study, the mean consumption of some foods such as raw onions, fried onions, cucumbers and salted vegetables, meat, eggs, dairy, tea and chocolate was significantly higher than control group. Although the mean consumption of smoked foods, canned foods, processed foods (such as sausages, burgers), salt and grains in the case group was more than control group, the difference was not statistically significant. It is worth mentioning that consumption of garlic, fermented pickles, bread and rice, solid oil and butter and meat in the control group was more than the case group. In most studies, there was an inverse relationship between gastric cancer and consumption of fruits and vegetables. However, similar to our study, no significant relationship was observed between gastric cancer and consumption of fruits and vegetables in the studies of Sanchez et al. and Sriamporn et al (Sanchez-Diez, Hernandez-Mejia, \& Cueto-Espinar, 1992; Sriamporn et al., 2002). According to the study of Zyckute et al., consumption of raw vegetable was inversely associated with risk of gastric cancer, there was no significant relationship between consumption of citrus or other fruits and risk of gastric cancer (Zickute et al., 2004).

According to our study, tea consumption in case group was significantly higher than the control group. However, according to the study of Yi et al. and Hassan et al., tea has a protective role for cancer (Hassan, Hussein, \& Saeed, 2015; Lin et al., 2014). This difference may be due to difference in dietary habits of these regions, particularly the type of tea consumed, method of making and level of consumption. In the present study, red meat consumption was significantly in the case group. Although fish consumption was higher in the case group, the difference was not significant. The present study is similar to the studies by Zhu et al., which indicated that red meat is an independent risk factor for gastric cancer (Zhu et al., 2013). According to the study of Pourfarzi et al. and Wu et al., fish consumption was associated with reduction in the risk of gastric cancer(Pourfarzi, Whelan, Kaldor, \& Malekzadeh, 2009; Wu et al., 2011). In this study, salt consumption in the case group was more than control group, but the difference was not statistically significant. In many similar studies, excessive consumption of salt and salted foods increased the risk of gastric cancer (Wang, Terry, \& Yan, 2009). Contrary to our study, bread and rice consumption in the control group was more than case group. According to the studies by Oisoet al., consumption of these materials and their products was associated with increased risk of gastric cancer (Oiso, 1975). However, 
similar to our study, bread consumption was more in the case group in the study of La Vecchiaet al (La Vecchia, Negri, Decarli, D'Avanzo, \& Franceschi, 1987). This difference may be due to excessive use of pesticides in farming to produce rice and wheat and the consumption of baking soda to cook bread. In addition, although sugar consumption was high in case group, it was not significant. According to the study of Key et al., sugar consumption increased the risk of gastric cancer (Key, Allen, Spencer, \& Travis, 2002). Since the dietary pattern in this study was analyzed within one month and considering that gastric cancer was diagnosed in these patients long before the beginning of this study, physicians suggest dietary habits. Therefore, reducing the consumption of foods that are known as risk factors for gastric cancer and increasing the consumption of foods that have protective effects differentiates this study from other studies. As mentioned earlier, there are considerable differences in risk factors for gastric cancer in the studies conducted in various regions.

\section{Conclusion}

Results of this study demonstrated that some foods such as fish, fruit, fresh vegetables, rice, salted foods and dairy products are extensively found in the dietary patterns of the families in Mazandaran. Therefore, consumption of these foods makes this study different from other studies. Also, different food consumption patterns play a critical role in the incidence of gastric cancer.

\section{Conflict of interest}

The authors report no conflicts of interest.

\section{Acknowledgments}

Authors acknowledgment the cooperation of department of social medicine, Babol university of medical sciences, Babol, Iran.

\section{References}

Crew, K. D., \& Neugut, A. I. (2006). Epidemiology of gastric cancer. World Journal ofGastroenterology: WJG, 12(3), 354-362. http://doi.org/10.3748/wjg.v12.i3.354

Derakhshan, M. H. (2013). Environmental and lifestyle risk factors of gastric cancer. Archives of Iranian medicine, 16(6), 358. https://doi.org/013166/AIM.0010

Edgren, G., Hjalgrim, H., Rostgaard, K., Norda, R., Wikman, A., Melbye, M., \& Nyrén, O. (2010). Risk of gastric cancer and peptic ulcers in relation to ABO blood type: a cohort study. American journal of epidemiology, 172(11), 1280-1285. https://doi.org/10.1093/aje/kwq299.

Fallah,R. F., \& Ebrahimpour, S. (2015). Garlic and Its Effects on Diseases. Crescent Journal of Medical and Biological Sciences, 2(2), 69-70.

González, C. A., Pera, G., Agudo, A., Bueno-de-Mesquita, H. B., Ceroti, M., Boeing, H., . . Carneiro, F. (2006). Fruit and vegetable intake and the risk of stomach and oesophagus adenocarcinoma in the European Prospective Investigation into Cancer and Nutrition (EPIC-EURGAST). International journal of cancer, 118(10), 2559-2566. https://doi.org/10.1002/ijc.21678.

Hassan, S., Hussein, A. J., \& Saeed, A. K. (2015). Role of green tea in reducing epidermal thickness upon ultraviolet light-B injury in BALB/c mice. Advances in Biology, 2015.

Hou, I.-C., Amarnani, S., Chong, M. T., \& Bishayee, A. (2013). Green tea and the risk of gastric cancer: $\begin{array}{llll}\text { epidemiological } & \text { evidence. World } J \text { Gastroenterol, } & \text { 19(24), 3713-3722. }\end{array}$ https://doi.org/10.3748/wjg.v19.i24.3713

Hu, B., El Hajj, N., Sittler, S., Lammert, N., Barnes, R., \& Meloni-Ehrig, A. (2012). Gastric cancer: Classification, histology and application of molecular pathology. Journal of gastrointestinal oncology, 3(3), 251-261. https://doi.org/10.3978/j.issn.2078-6891.2012.021

Jakszyn, P., \& González, C. A. (2006). Nitrosamine and related food intake and gastric and oesophageal cancer risk: a systematic review of the epidemiological evidence. World journal of gastroenterology, 12(27), 4296.

Key, T. J., Allen, N. E., Spencer, E. A., \& Travis, R. C. (2002). The effect of diet on risk of cancer. The Lancet, 360(9336), 861-868. https://doi.org/10.1016/S0140-6736(02)09958-0.

Kusters, J. G., van Vliet, A. H., \& Kuipers, E. J. (2006). Pathogenesis of Helicobacter pylori infection. Clinical microbiology reviews, 19(3), 449-490. https://doi.org/10.1128/CMR.00054-05.

La Vecchia, C., Negri, E., Decarli, A., D'Avanzo, B., \& Franceschi, S. (1987). A case-control study of diet and gastric cancer in Northern Italy. International journal of cancer, 40(4), 484-489. 
Lin, Y.-w., Hu, Z.-h., Wang, X., Mao, Q.-q., Qin, J., Zheng, X.-y., \& Xie, L.-p. (2014). Tea consumption and prostate cancer: an updated meta-analysis. World Journal of Surgical Oncology, 12, 38-38. https://doi.org/10.1186/1477-7819-12-38

Mager, D. (2006). Bacteria and cancer: cause, coincidence or cure? A review. Journal of translational medicine, 4(1), 14. https://doi.org/10.1186/1479-5876-4-14.

Malekzadeh, R. (2013). A case-control study of the relationship between gastric cancer and meat consumption in Iran. Archives of Iranian medicine, 16(6), 324.

Malekzadeh, R., Derakhshan, M. H., \& Malekzadeh, Z. (2009). Gastric cancer in Iran: epidemiology and risk factors. Archives of Iranian medicine, 12(6), 576-83.

Oiso, T. (1975). Incidence of stomach cancer and its relation to dietary habits and nutrition in Japan between 1900 and 1975. Cancer research, 35(11 Part 2), 3254-3258.

Park, J. Y., von Karsa, L., \& Herrero, R. (2014). Prevention strategies for gastric cancer: a global perspective. Clin Endosc, 47(6), 478-489. https://doi.org/10.5946/ce.2014.47.6.478.

Pourfarzi, F., Whelan, A., Kaldor, J., \& Malekzadeh, R. (2009). The role of diet and other environmental factors in the causation of gastric cancer in Iran-a population based study. International journal of cancer, 125(8), 1953-1960. https://doi.org/10.1002/ijc.24499.

Sanchez-Diez, A., Hernandez-Mejia, R., \& Cueto-Espinar, A. (1992). Study of the relation between diet and gastric cancer in a rural area of the Province of Leon, Spain. European journal of epidemiology, 8(2), 233-237.

Sriamporn, S., Setiawan, V., Pisani, P., Suwanrungruang, K., Sirijaichingkul, S., Mairiang, P., \& Parkin, D. M. (2002). Gastric cancer: the roles of diet, alcohol drinking, smoking and Helicobacter pylori in Northeastern Thailand. Asian Pac J Cancer Prev, 3(345), 52.

Thun, M. J., DeLancey, J. O., Center, M. M., Jemal, A., \& Ward, E. M. (2010). The global burden of cancer: priorities for prevention. Carcinogenesis, 31(1), 100-110. https://doi.org/10.1093/carcin/bgp263

Tiso, M., \& Schechter, A. N. (2015). Nitrate reduction to nitrite, nitric oxide and ammonia by gut bacteria under physiological conditions. PloS one, 10(3), e0119712. https://doi.org/10.1371/journal.pone.0119712

Wang, X.-Q., Terry, P. D., \& Yan, H. (2009). Review of salt consumption and stomach cancer risk: epidemiological and biological evidence. World J Gastroenterol, 15(18), 2204-2213.

Wu, S., Liang, J., Zhang, L., Zhu, X., Liu, X., \& Miao, D. (2011). Fish consumption and the risk of gastric cancer: systematic review and meta-analysis. BMC cancer, 11(1), 26. https://doi.org/10.1186/1471-2407-11-26.

Zali, H., Rezaei-Tavirani, M., \& Azodi, M. (2011). Gastric cancer: prevention, risk factors and treatment. Gastroenterology and Hepatology from bed to bench, 4(4).

Zhu, H., Yang, X., Zhang, C., Zhu, C., Tao, G., Zhao, L., . . Dai, S. (2013). Red and processed meat intake is associated with higher gastric cancer risk: a meta-analysis of epidemiological observational studies. PloS one, 8(8), e70955. https://doi.org/10.1371/journal.pone.0070955.

Zickute, J., Strumylaite, L., Dregval, L., Petrauskiene, J., Dudzevicius, J., \& Stratilatovas, E. (2004). Vegetables and fruits and risk of stomach cancer. Medicina (Kaunas, Lithuania), 41(9), 733-740.

\section{Copyrights}

Copyright for this article is retained by the author(s), with first publication rights granted to the journal.

This is an open-access article distributed under the terms and conditions of the Creative Commons Attribution license (http://creativecommons.org/licenses/by/4.0/). 